\title{
Suitability of gamma irradiation for preserving fresh-cut watercress quality during cold storage
}

José Pinela ${ }^{\mathrm{a}, \mathrm{b}}$, João C.M. Barreira ${ }^{\mathrm{a}, \mathrm{b}}$, Lillian Barros ${ }^{\mathrm{a}}$, Sandra Cabo Verde ${ }^{\mathrm{c}}$, Amilcar L. Antonio $^{\mathrm{a}}$, Ana Maria Carvalho ${ }^{\mathrm{a}}$, M. Beatriz P.P. Oliveira ${ }^{\mathrm{b}}$, Isabel C.F.R. Ferreira ${ }^{\mathrm{a}, *}$

${ }^{a}$ Mountain Research Centre (CIMO), ESA, Polytechnic Institute of Bragança, Campus de Santa Apolónia, 1172, 5301-855 Bragança, Portugal

${ }^{\mathrm{b}}$ REQUIMTE/LAQV, Faculty of Pharmacy, University of Porto, Rua Jorge Viterbo Ferreira, $n^{\circ} 228,4050-313$ Porto, Portugal

${ }^{c}$ Centro de Ciências e Tecnologias Nucleares (C2TN), Instituto Superior Técnico, Universidade de Lisboa, E.N. 10, 2695-066 Bobadela, Portugal

* Author to whom correspondence should be addressed (Isabel C.F.R. Ferreira; e-mail: iferreira@ipb.pt; telephone +351-273-303219; fax +351-273-325405).

Running title: Gamma irradiation for preserving fresh-cut watercress 


\begin{abstract}
The suitability of gamma irradiation (1,2 and $5 \mathrm{kGy})$ for preserving quality parameters of fresh-cut watercress (Nasturtium officinale $\mathrm{R}$. Br.) during storage at $4 \pm 1{ }^{\circ} \mathrm{C}$ for $7 \mathrm{~d}$ was investigated. The storage time decreased the protein content and the main carbohydrates, and increased the levels of malic and fumaric acids, sucrose and monoand polyunsaturated fatty acids (MUFA and PUFA). The different irradiation doses did not caused any significant colour change. In general, the $2 \mathrm{kGy}$ dose favoured PUFA and was the most suitable to preserve the overall postharvest quality of fresh-cut watercress during cold storage. In turn, the $5 \mathrm{kGy}$ dose better preserved the antioxidant activity and total flavonoids and favoured MUFA, tocopherols and total phenolics, thus originating a final product with enhanced functional properties. Therefore, the suitability of gamma irradiation for preserving fresh-cut watercress quality during cold storage was demonstrated.
\end{abstract}

Keywords: Nasturtium officinale, fresh-cut watercress, gamma irradiation, cold storage, postharvest quality, antioxidant activity 


\section{Introduction}

Watercress (Nasturtium officinale $\mathrm{R}$. Br.) is a rapidly growing, aquatic or semi-aquatic perennial plant of the Brassicaceae family widely consumed in salads. It feature sharp, peppery and slightly tangy taste and contains health-promoting phytochemicals endowed with therapeutic properties (Rose, Won, Ong, \& Whiteman, 2005; Sadeghi et al., 2014). Its consumption as a fresh-cut product has increased in recent years, as well as the global market of minimally processed vegetables (Pinela \& Ferreira, 2015; Sillani \& Nassivera, 2015). This demand is driven by the growing interest in the role of food in promoting the human health and well-being and to meet consumer needs for fresh-like and more convenient foods. Besides, consumers are receptive to innovations that enhance the quality and nutritional value of food and critical of technologies that excessively modify the original product or could be dangerous to human health and the environment (Sillani \& Nassivera, 2015).

Minimally processed vegetables are highly perishable because of exposed internal tissues, lack of skin or cuticle for protection and elevated metabolism, so that the deterioration is faster than in intact ones (Francis et al., 2012). Meanwhile, there are some concerns surrounding efficacy of the commonly used sanitizing methods. Chemical agents do not provide an efficient microbial reduction, besides being perceived negatively by the consumers, dangerous for human health and harmful to the environment (Ramos, Miller, Brandão, Teixeira, \& Silva, 2013). In turn, the conventional thermal treatments may negatively affect several quality parameters of these perishable foods (Pinela \& Ferreira, 2015). For this reasons, innovative and more sustainable postharvest treatments based on non-thermal physical technologies are being investigated. 
The gamma irradiation treatment has become an effective means of improving both safety and shelf-life of food products. Its commercial use is steadily growing because it provides a safe solution to quarantines and is tolerated by more fresh commodities than any alternative treatment in use (Hallman, 2016). A joint FAO/IAEA/WHO Expert Committee on the wholesomeness of irradiated foods has ruled that foods subjected to irradiation doses up to $10 \mathrm{kGy}$ are safe and do not require toxicological testing (WHO, 1999). For fresh horticultural products, irradiation treatments have been used to prevent sprouting and post-packaging contamination, delay postharvest ripening, maturation and senescence and thereby extend the shelf-life and reduce food losses (ICGFI, 1999). Examples of minimally processed vegetables treated by gamma irradiation, aiming both quality preservation and shelf-life extension, include arugula (Nunes et al., 2013), spinach (Fan \& Sokorai, 2011), cauliflower (Vaishnav, Adiani, \& Variyar, 2015), ash gourd (Tripathi, Chatterjee, Vaishnav, Variyar, \& Sharma, 2013), bamboo shoots (Zeng, Luo, Xie, \& Feng, 2015), coriander, parsley, lettuce and watercress (Trigo et al., 2009). However, little information is still available regarding changes on physical, chemical or bioactive properties, as well as on the shelf-life of minimally processed vegetables. In this sense, this study was carried out to evaluate the suitability of gamma irradiation at different doses (1, 2 and $5 \mathrm{kGy})$ for preserving visual, nutritional and antioxidant quality parameters of fresh-cut watercress during cold storage at $4 \pm 1^{\circ} \mathrm{C}$ for $7 \mathrm{~d}$.

\section{Materials and methods}

\subsection{Standards and reagents}

Amber Perspex routine dosimeters, Batch X, were purchased from Harwell Company (Oxfordshire, UK). Acetonitrile 99.9\%, n-hexane 95\% and ethyl acetate 99.8\% were of HPLC grade from Fisher Scientific (Lisbon, Portugal). The fatty acids methyl ester 
(FAME) reference standard mixture 37 (standard 47885-U), other individual fatty acid isomers, tocopherols $\left(\alpha-, \beta-\right.$, and $\gamma$-isoforms), sugars $\left({ }_{D}(-)\right.$-fructose, $\mathrm{D}^{(+)}$-glucose anhydrous, $\mathrm{D}^{(+)}$-melezitose hydrate, $\mathrm{D}^{(+)}$-sucrose), organic acids (citric, malic, oxalic and fumaric acids), trolox (6-hydroxy-2,5,7,8-tetramethylchroman-2-carboxylic acid), gallic acid and catechin standards were purchased from Sigma (St. Louis, MO, USA). Racemic tocol, $50 \mathrm{mg} / \mathrm{mL}$, was purchased from Matreya (PA, USA). 2,2-Diphenyl-1picrylhydrazyl (DPPH') as obtained from Alfa Aesar (Ward Hill, MA, USA). All other chemicals and solvents were of analytical grade and purchased from common sources. Water was treated in a Milli-Q water purification system (Millipore, model A10, Billerica, MA, USA).

\subsection{Sampling and samples preparation}

Wild samples of watercress (Nasturtium officinale R. Br., synonym of Rorippa nasturtium-aquaticum (L.) Hayek) were hand-harvested in February 2014 in a local stream in the civil parish of Calvelhe, municipality of Bragança, Portugal, considering local consumers' sites, criteria and preferences, such as the season and phenological stage. Taxonomic identification of the plant material was confirmed by the botanist Dr. Ana Maria Carvalho, from the Polytechnic Institute of Bragança, Portugal. A voucher specimen was deposited in the Herbarium of the School of Agriculture of Bragança. The use of wild-harvested samples instead of ones from commercial sources allowed having control over the postharvest age of the plant. In the same day, healthy and undamaged aerial parts (tender stems and leaves) were hand-picked (removing yellow leaves, thicker stems and roots), rinsed in tap water and drained to eliminate excess water. Then, a portion of watercress was immediately analyzed (non-stored control) and the remaining fresh material was packaged in $11.5 \mathrm{~cm} \times 15 \mathrm{~cm}$ sterilized packages made 
from low-density polyethylene film (thickness $63 \mu \mathrm{m}$ ) using the passive modification mode (air). Forty packages containing $20 \mathrm{~g}$ of sample were prepared.

\subsection{Samples irradiation and storage}

Packaged samples were divided into four groups of 10 packages and submitted to 1,2 and $5 \mathrm{kGy}$ of gamma-rays (predicted doses). The other group was a non-irradiated (0 kGy) control that followed all the experiment. The irradiation was performed one day after harvest in an cobalt-60 experimental chamber (Precisa 22, Graviner Manufacturing Company Ltd., UK) located at C2TN (Centre for Nuclear Sciences and Technologies), in Portugal, with four sources and a total activity of 177 TBq (4.78 kCi; February 2014). During the irradiation process, amber Perspex routine dosimeters were used to measure the distribution of the absorbed energy and to determine the maximum $\left(D_{\max }\right)$ and the minimum $\left(D_{\min }\right)$ dose absorbed by the samples following the procedure previously described by Fernandes et al. (2012). The measured average doses were $1.2 \pm 0.1 \mathrm{kGy}$, $2.2 \pm 0.2 \mathrm{kGy}$ and $5.2 \pm 0.4 \mathrm{kGy}$ for the samples irradiated at the predicted doses of 1,2 and $5 \mathrm{kGy}$, respectively. For simplicity, the predicted dose values were considered in the text. The estimated dose rate for the irradiation position was $1.6 \mathrm{kGy} / \mathrm{h}$ and the dose uniformity ratio $\left(D_{\max } / D_{\min }\right)$ was 1.5 . Irradiated and non-irradiated packaged samples were stored in the dark at $4 \pm 1{ }^{\circ} \mathrm{C}$ for $7 \mathrm{~d}$.

\subsection{Quality analysis}

\subsubsection{Colour parameters}

Watercress samples were placed on a black surface to reduce external interferences and data were collected on the adaxial surface of nine randomly selected leaves with a colorimeter (model CR-400; Konica Minolta Sensing Inc., Japan) previously calibrated 
using the standard white plate (Pereira et al., 2015a). Using illuminant $\mathrm{C}$ and the diaphragm opening of $8 \mathrm{~mm}$, the CIE $L^{*} a^{*} b^{*}$ colour space values were registered through the computerized system using a colour data software "Spectra Magic Nx" (version CM-S100W 2.03.0006). Average values were considered to determine the colour coordinates, where $L^{*}$ represents lightness, $a^{*}$ represents chromaticity on a green $(-)$ to red $(+)$ axis, and $b^{*}$ represents chromaticity on a blue $(-)$ to yellow $(+)$ axis.

\subsubsection{Total soluble solids and $\mathrm{pH}$}

Watercress samples were ground and the grinding paste was subsequently filtered through Whatman No. 4 paper. The total soluble solids (TSS) content (\%) in the squeezed juice was measured with a digital hand refractometer (model HI 96801, Hanna Instruments, Woonsocket, RI, USA) and the $\mathrm{pH}$ with a digital pH-meter (model $\mathrm{pH} 211$, Hanna Instruments, Woonsocket, RI, USA).

\subsubsection{Proximate composition}

Watercress samples were analyzed for moisture, proteins, fat, ash and carbohydrates using the AOAC procedures (AOAC, 2005). Samples were lyophilised (FreeZone 4.5, Labconco, Kansas City, MO, USA) and reduced to a fine powder (20 mesh) for analysis of proteins, fat and ash. Briefly, the crude protein content $(\mathrm{N} \times 6.25)$ was estimated by the macro-Kjeldahl method, using an automatic distillation and titration unit (model UDK152, VELP Scientifica, Italy); the crude fat was determined by extracting a known weight of powdered sample with petroleum ether, using a Soxhlet apparatus; the ash content was determined by incineration at $600 \pm 15^{\circ} \mathrm{C}$; and total carbohydrates were calculated by difference according to the equation: $100-\left(\mathrm{m}_{\text {moisture }}+\mathrm{m}_{\text {proteins }}+\mathrm{m}_{\mathrm{fats}}+\right.$ $\left.\mathrm{m}_{\text {ashes}}\right)$. The results were expressed as g per $100 \mathrm{~g}$ of fresh weight (fw). The total energy 
was calculated according to the equation: $4 \times\left(m_{\text {proteins }}+m_{\text {carbohydrates }}\right)+9 \times\left(m_{\text {fats }}\right)$ and expressed as kcal per $100 \mathrm{~g}$ of fresh weight (fw).

\subsubsection{Free sugars}

Free sugars were determined by high performance liquid chromatography (HPLC) coupled to a refraction index (RI) detector as described by Pereira, Barros, Carvalho and Ferreira (2011). Briefly, lyophilized powdered samples $(1 \mathrm{~g})$ were spiked with melezitose (internal standard, $5 \mathrm{mg} / \mathrm{mL}$ ) and extracted with $40 \mathrm{~mL}$ of $80 \%$ aqueous ethanol at $80{ }^{\circ} \mathrm{C}$ for $30 \mathrm{~min}$. The mixture was centrifuged at $15,000 \mathrm{~g}$ (Centurion K24OR-2003 refrigerated centrifuge) for $10 \mathrm{~min}$ and the supernatant was concentrated under reduced pressure (rotary evaporator Büchi R-210, Flawil, Switzerland) and defatted with ethyl ether. After concentration at $40{ }^{\circ} \mathrm{C}$, the residues were dissolved in 5 $\mathrm{mL}$ of water and filtered through $0.2 \mu \mathrm{m}$ nylon filters for subsequent injection. The HPLC equipment consisted of an integrated system with a Smartline system 1000 pump (Knauer, Berlin, Germany), a Smartline Manager 5000 degasser, an AS-2057 autosampler (Jasco, Easton, MD, USA) and a Smartline 2300 RI detector. The chromatographic separation was achieved with a Eurospher 100-5 $\mathrm{NH}_{2}$ column $(4.6 \times$ $250 \mathrm{~mm}, 5 \mathrm{~mm}$, Knauer) operating at $30^{\circ} \mathrm{C}$ in a $7971 \mathrm{R}$ Grace oven. The mobile phase was acetonitrile/deionized water, $70: 30(\mathrm{v} / \mathrm{v})$, at a flow rate of $1 \mathrm{~mL} / \mathrm{min}$. The compounds were identified by chromatographic comparisons with authentic standards and quantified using the internal standard method. The results were expressed in $\mathrm{mg}$ per $100 \mathrm{~g}$ of fresh weight (fw).

\subsubsection{Organic acids}


Organic acids were analyzed by ultra fast liquid chromatography (UFLC) coupled to a photodiode array (PDA) detector according to Pereira, Barros, Carvalho and Ferreira (2013). Briefly, fresh tissue (9 g) was ground and the grinding paste was subsequently extracted by stirring with $25 \mathrm{~mL}$ of meta-phosphoric acid $\left(25^{\circ} \mathrm{C}\right.$ at $\left.150 \mathrm{rpm}\right)$ for $45 \mathrm{~min}$ and subsequently filtered through Whatman No. 4 paper. Before injection, samples were filtered through $0.2 \mu \mathrm{m}$ nylon filters. The analysis was carried out with a Shimadzu $20 \mathrm{~A}$ series UFLC (Shimadzu Corporation, Kyoto, Japan). The chromatographic separation was achieved with a SphereClone (Phenomenex, Torrance, CA, USA) reverse phase $\mathrm{C}_{18}$ column $(5 \mu \mathrm{m}, 250 \times 4.6 \mathrm{~mm}$ i.d $)$ thermostated at $35^{\circ} \mathrm{C}$. The elution was performed with sulphuric acid $3.6 \mathrm{mM}$ at a flow rate of $0.8 \mathrm{~mL} / \mathrm{min}$. Detection was carried out in a PDA detector, using 215 and $245 \mathrm{~nm}$ (for ascorbic acid) as preferred wavelengths. The organic acids found were quantified by comparison of the area of their peaks with calibration curves obtained from commercial standards of each compound, i.e., oxalic, malic, citric and fumaric acids. The results were expressed in mg per $100 \mathrm{~g}$ of fresh weight (fw).

\subsubsection{Fatty acids}

Fatty acids were analyzed by gas chromatography with flame ionization detection (GCFID)/capillary column as described previously by Barros, Carvalho, Sá Morais and Ferreira (2010). Briefly, the fatty acids obtained after Soxhlet extraction were methylated with methanol:sulfuric acid:toluene 2:1:1 (v:v:v) during at least $12 \mathrm{~h}$ in a bath at $50{ }^{\circ} \mathrm{C}$ and $160 \mathrm{rpm}$. Then, deionised water was added to obtain a phase separation and the FAME were recovered with diethyl ether by shaking in vortex. The upper phase was dehydrated with sodium sulfate anhydrous and filtered through $0.2 \mu \mathrm{m}$ nylon filters for subsequent injection. The analysis was carried out with a DANI model 
GC 1000 instrument equipped with a split/splitless injector, a FID detector at $260{ }^{\circ} \mathrm{C}$ and a Macherey-Nagel column $\left(30 \mathrm{~m} \times 0.32 \mathrm{mmID} \times 0.25 \mu \mathrm{m} \mathrm{d}_{f}\right)$. The oven temperature programme was as described by Pereira et al. (2011). The identification was made by comparing the relative retention times of FAME peaks from samples with standards. The results were recorded and processed using CSW 1.7 software (DataApex 1.7) and expressed in relative percentage of each fatty acid.

\subsubsection{Tocopherols}

Tocopherols were determined by HPLC coupled to a fluorescence (FP-2020; Jasco) detector following the procedures previously described by Pereira et al. (2011). Briefly, lyophilized powdered samples $(500 \mathrm{mg})$ were spiked with a BHT solution $(10 \mathrm{mg} / \mathrm{mL})$ and tocol (internal standard, $50 \mu \mathrm{g} / \mathrm{mL}$ ) and homogenized with methanol (4 mL) by shaking in vortex $(1 \mathrm{~min})$ and then with hexane $(4 \mathrm{~mL})$. After that, a saturated $\mathrm{NaCl}$ aqueous solution $(2 \mathrm{~mL})$ was added, the mixture was homogenized, centrifuged ( $5 \mathrm{~min}$, $4000 g$ ) and the clear upper layer was collected. The extraction was repeated twice with hexane. The obtained extracts were dried under a nitrogen stream, redissolved in $2 \mathrm{~mL}$ of n-hexane, dehydrated, and filtered through $0.22 \mu \mathrm{m}$ disposable LC filters for subsequent injection. The analysis was carried out in the HPLC system described above connected to the FP-2020 detector programmed for excitation at $290 \mathrm{~nm}$ and emission at $330 \mathrm{~nm}$. The chromatographic separation was achieved with a Polyamide II normalphase column $(250 \times 4.6 \mathrm{~mm}$; YMC Waters $)$ operating at $30^{\circ} \mathrm{C}$. The mobile phase was a mixture of $\mathrm{n}$-hexane and ethyl acetate $(70: 30, \mathrm{v} / \mathrm{v})$ at a flow rate of $1 \mathrm{~mL} / \mathrm{min}$. The compounds were identified by chromatographic comparisons with authentic standards and quantified using the internal standard method. The results were expressed in mg per $100 \mathrm{~g}$ of fresh weight (fw). 


\subsection{Antioxidant properties evaluation}

\subsubsection{General}

Watercress extracts were prepared according to procedures previously described by Pereira et al. (2011 and 2015a). Briefly, a fine dried powder (20 mesh; $\sim 1 \mathrm{~g}$ ) was stirred (150 rpm) with $50 \mathrm{~mL}$ of methanol:water $(80: 20, \mathrm{v} / \mathrm{v})$ for $1 \mathrm{~h}$ at $25^{\circ} \mathrm{C}$. The supernatant was filtered through Whatman No. 4 paper and the residue was re-extracted with an additional portion of solvent $(50 \mathrm{~mL})$. The combined extracts were then evaporated at $35{ }^{\circ} \mathrm{C}$ under reduced pressure, redissolved in the same solvent (final concentration of 5 $\mathrm{mg} / \mathrm{mL}$ ) and successively diluted to different concentrations.

\subsubsection{Antioxidant activity}

Four in vitro assays were performed to evaluate the hydromethanolic extracts antioxidant activity (Pereira et al., 2011 and 2015b): DPPH $^{\circ}$ scavenging activity, reducing power (measured by ferricyanide Prussian blue assay), $\beta$-carotene blanching inhibition, and thiobarbituric acid reactive substances (TBARS) formation inhibition. Briefly, the $\mathrm{DPPH}^{*}$ scavenging activity and the reducing power assays were performed using an ELX800 Microplate Reader (Bio-Tek Instruments, Inc; Winooski, VT, USA). The reduction of $\mathrm{DPPH}^{*}$ was determined by measuring the absorbance at $515 \mathrm{~nm}$ and calculated as a percentage of $\mathrm{DPPH}^{*}$ discolouration using the equation: $\left[\left(\mathrm{A}_{\mathrm{DPPH}}-\right.\right.$ $\left.\left.A_{S}\right) / A_{D P P H}\right] \times 100$, where $A_{D P P H}$ is the absorbance of the $\mathrm{DPPH}^{*}$ solution and $\mathrm{A}_{\mathrm{S}}$ is the absorbance of the solution containing the sample extract. The reducing power was evaluated by the capacity to convert $\mathrm{Fe}^{3+}$ into $\mathrm{Fe}^{2+}$, measuring the absorbance at 690 nm. The $\beta$-carotene bleaching inhibition was evaluated by measuring the capacity to neutralize linoleate free radicals, which was monitored at $470 \mathrm{~nm}$ in a Model 200 
spectrophotometer (AnalytikJena, Jena, Germany), and calculated using the equation: $\left(\mathrm{A}_{\beta \mathrm{T} 2} / \mathrm{A}_{\beta \mathrm{TT}}\right) \times 100$, where $\mathrm{A}_{\beta \mathrm{T} 2}$ is the absorbance of the emulsion after $2 \mathrm{~h}$ of incubation at $50{ }^{\circ} \mathrm{C}$ and $\mathrm{A}_{\beta \text { T0 }}$ is the initial absorbance. The TBARS formation inhibition was evaluated in porcine brain homogenates. The colour intensity of the malondialdehydethiobarbituric acid (MDA-TBA) complex formed during heating at $80{ }^{\circ} \mathrm{C}$ for $20 \mathrm{~min}$ was measured at $532 \mathrm{~nm}$, and the inhibition ratio calculated using the equation: [(A B) $/ \mathrm{A}] \times 100 \%$, where $\mathrm{A}$ and $\mathrm{B}$ correspond to the absorbance of the control and the sample solution, respectively. The results were expressed in $\mathrm{EC}_{50}$ values $(\mathrm{mg} / \mathrm{mL})$, i.e., sample concentration providing $50 \%$ of antioxidant activity or 0.5 of absorbance in the reducing power assay. Trolox was used as positive control.

\subsubsection{Total phenolics and flavonoids}

The total phenolic content was determined by the Folin-Ciocalteu method with slight modifications (Pereira et al., 2011) in the hydromethanolic extracts concentrated at $0.625 \mathrm{mg} / \mathrm{mL}$. This assay is based on the formation of a blue-coloured complex between the molybdenum and tungsten present in the Folin-Ciocalteu reagent upon reaction with reducing agents, which is monitored at $765 \mathrm{~nm}$. The standard curve was calculated using gallic acid and the results were expressed as mg of gallic acid equivalents (GAE) per $g$ of extract.

The total flavonoid content was determined using the aluminum chloride colorimetric method as described by the authors (Barros et al., 2010) in the extracts concentrated at $1.25 \mathrm{mg} / \mathrm{mL}$. This assay is based on the formation of a complex flavonoid-aluminum, which is monitored at $510 \mathrm{~nm}$. The standard curve was calculated using catechin and the results were expressed as $\mathrm{mg}$ of catechin equivalents (CE) per $\mathrm{g}$ of extract. 


\subsection{Statistical analysis}

Replicates of each treatment were divided into three batches and independently analyzed. All the quality analyses were carried out in triplicates. Data were expressed as mean \pm standard deviation. All statistical tests were performed at a $5 \%$ significance level using SPSS Statistics software (IBM SPSS Statistics for Windows, Version 22.0. Armonk, NY: IBM Corp.).

The differences among treatments were analyzed using the one-way analysis of variance (ANOVA). The fulfilment the ANOVA requirements, specifically the normal distribution of the residuals and the homogeneity of variance, was tested by means of the Shapiro Wilk's and the Levene's tests, respectively. All dependent variables were compared using Tukey's honestly significant difference (HSD) or Tamhane's T2 multiple comparison tests, when homoscedasticity was verified or not, respectively. Furthermore, a linear discriminant analysis (LDA) was used to evaluate the effect of gamma irradiation on the overall postharvest quality of watercress during cold storage. A stepwise technique, using the Wilks' $\lambda$ method with the usual probabilities of $F$ (3.84 to enter and 2.71 to remove), was applied for variable selection. This procedure uses a combination of forward selection and backward elimination processes, where the inclusion of a new variable is preceded by ensuring that all variables selected previously remain significant. With this approach, it is possible to determine which of the independent variables account most for the differences in the average score profiles of the different treatments. To verify the significance of canonical discriminant functions, the Wilks' $\lambda$ test was applied. A leaving-one-out cross-validation procedure was carried out to assess the model performance.

\section{Results and discussion}


The suitability of the irradiation treatment for preserving postharvest quality parameters depends on the applied dose and plant material under investigation (Trigo et al., 2009). During irradiation process, free radicals and reactive species are generated due to the radiolysis of water, which are capable of breaking chemical bonds and modify various biomolecules (Fanaro, Hassimotto, Bastos, \& Villavicencio, 2015). Besides, fresh-cut vegetables are still living organisms composed by a wide range of bioactive compounds able to interact and protect the plant tissues from adverse postharvest conditions. In addition, hormetic effects can also be induced by ionizing radiation (Shama \& Alderson, 2005). Therefore, nonlinear dose-response effects of the irradiation treatment on the evaluated quality parameters can be expected during shelf-life.

\subsection{Effects on colour, TSS and $\mathrm{pH}$}

Colour plays a key role in food acceptability and is more important than flavour or texture in the initial food-selection process. Therefore, colour loss is one of the major external postharvest problems. Based on the one-way ANOVA $p$-values it was possible to conclude that the treatment induced significant changes on the $L^{*}$ and $b^{*}$ colour values, but had no effect on greenness ( $a^{*}$ value) (Table 1). The observed changes were attributed to the storage time, since those recorded in stored samples did not differ significantly from each other. The yellowing $\left(b^{*}\right)$ just differed significantly between non-stored and non-irradiated stored samples. The increased lightness $\left(L^{*}\right)$ of the stored samples, especially those non-irradiated and irradiated at 2 and $5 \mathrm{kGy}$, suggested incipient yellowing of the leaves. Silveira, Araneda, Hinojosa and Escalona (2014) also reported a slight increase in lightness of watercress leaves stored at $5{ }^{\circ} \mathrm{C}$ under some non-conventional modified atmospheres. In contrast, a decrease was reported for watercress samples stored at $5^{\circ} \mathrm{C}$ for $14 \mathrm{~d}$ and previously sanitized using chemical 
agents (Hinojosa et al., 2012). Other study demonstrated that gamma irradiation doses up to $1 \mathrm{kGy}$ had no effect on watercress colour (Trigo et al., 2009). The authors also reported an increase in $L^{*}$ values of irradiated and non-irradiated lettuce samples stored at $4{ }^{\circ} \mathrm{C}$.

The TSS content and $\mathrm{pH}$ also allow the indirect evaluation of changes in sensory attributes (i.e., flavour) that have significant influence in the consumers' evaluation of the product (Barrett, Beaulieu, \& Shewfelt, 2010). The TSS content decreased in nonirradiated samples and in those irradiated at $5 \mathrm{kGy}$ (Table 1). The consumption of the sugars included in the TSS fraction during storage by the plant metabolic processes may justify this reduction (Dey \& Harborne, 1997). The $2 \mathrm{kGy}$ dose preserved the initial TSS content, which was increased with the $1 \mathrm{kGy}$ dose. Curiously, the last samples also revealed the sharpest increase of total organic acids (which will be discussed below). As it is known, TSS include mainly soluble sugars but also small amounts of organic acids. In turn, the initial $\mathrm{pH}$ values were only maintained in samples irradiated at $5 \mathrm{kGy}$. Nevertheless, these values were always higher than 5.34. The evolution of these physicochemical parameters during storage may affect the sensorial properties of watercress, especially the sweetness and sourness sensation (Barrett et al., 2010). However, sensory analysis with a trained panel will be interesting to evaluate the samples acceptance.

\subsection{Effects on the proximate composition}

The nutritional composition of fresh and irradiated samples of watercress is presented in Table 2. From the one-way ANOVA $p$-values, it can be concluded that the treatment induced significant changes in all macronutrients, except for fat content. In general, the storage time decreased the protein and carbohydrates content and, consequently, the 
energetic contribution, independently of the irradiation dose. Just slight variations of moisture, ash and proteins were found among the irradiated samples, which did not differ in the carbohydrates content. A previous study of Pereira et al. (2011) reported a similar energetic contribution $(\sim 23.5 \mathrm{kcal} / 100 \mathrm{~g} \mathrm{fw})$ to that described in this study for control samples, but lower amounts of proteins ( $\sim 0.92 \mathrm{~g} / 100 \mathrm{~g} \mathrm{fw})$ and slightly higher levels of ash $(\sim 1.14 \mathrm{~g} / 100 \mathrm{~g} \mathrm{fw})$, fat $(0.20 \mathrm{~g} / 100 \mathrm{~g} \mathrm{fw})$ and carbohydrate $(4.51 \mathrm{~g} / 100 \mathrm{~g}$ fw) in watercress samples collected in the same region. This small difference in the reported values may be linked to variations on edafoclimatic conditions of the locations where the samples were collected, which may affect the plant composition during the growing season (Nikolopoulou, Grigorakis, Stasini, Alexis, \& Iliadis, 2007).

\subsection{Effects on sugars and organic acids}

The individual sugars and organic acid profiles are presented in Table 2. As it can be concluded from the one-way ANOVA $p$-values, the different irradiation doses induced significant changes in these hydrophilic compounds. In fresh samples, fructose was the most abundant sugar, followed by glucose and sucrose. The storage time decreased the amounts of fructose, glucose and total sugars, but increased the sucrose levels. This increase in sucrose was more marked in samples irradiated at $5 \mathrm{kGy}$, which also showed the lowest levels of fructose. The $2 \mathrm{kGy}$ dose was suitable to preserve high levels of fructose, glucose and total sugars, samples that revealed comparable amounts of fructose, sucrose and total sugars to those irradiated at $1 \mathrm{kGy}$. The observed decrease of fructose and glucose (reducing sugars) levels during storage can be attributed to the plant metabolic activity, which is higher in wounded tissues (Uritani \& Asahi, 1980). However, it is also known that irradiation may decrease the melting point and optical rotation of sugars, or even cause its degradation due to the direct action of gamma-rays 
and interaction with radiolytic products (Molins, 2001). The glycosidic bond of disaccharide can also be broken by irradiation (Molins, 2001), but higher levels of sucrose were found in stored samples. Most probably there was a mobilization of carbohydrates, hence its decline. Comparable results were found by Workneh, Osthoff and Steyn (2012) in tomato samples stored at $13{ }^{\circ} \mathrm{C}$ for $8 \mathrm{~d}$, in particular the decrease in glucose levels and the increase in sucrose. In addition to the sugars described herein, trehalose and raffinose were already detected in other watercress samples (Pereira et al., 2011); in which sucrose was the main sugar. Additionally, the total sugars content of our fresh samples was similar to that described by Pereira et al. (2011), i.e., $210 \mathrm{mg} / 100$ $\mathrm{g}$ fw.

Oxalic, malic, citric and fumaric acids were detected (Table 2), being oxalic acid the most abundant. The cold storage decreased the amounts of oxalic (except for the $1 \mathrm{kGy}$ dose) and citric acids, and increased the levels of malic, fumaric and total organic acids. The different irradiation doses favoured different organic acids: the highest values of oxalic, malic and fumaric acids were registered in samples irradiated at 1,2 and $5 \mathrm{kGy}$, respectively. Regarding citric acid, a dose dependent effect was observed, i.e., increasing the irradiation dose decreases the content in citric acid. This decrease may be attributed to the direct impact of gamma-rays or to the reaction with reactive intermediates of water radiolysis. The radiolytic decomposition of this organic acid in aqueous solutions was shown to increase steadily with the absorbed dose (Semelová, Čuba, John, \& Múčka, 2008). In our study, this trend was also verified for total organic acids. Moreover, malic acid may result from the radiolysis of citric acid (Apelblat, 2014). Curiously, the ascorbic acid was not detected in these samples or in those previously analyzed by Pereira et al. (2013). 


\subsection{Effects on fatty acids and tocopherols}

Lipids are one of the main targets of the attack of the free radicals generated during radiolysis. This attack is called lipid peroxidation and promotes the production of different reactive species (Ferreira et al., 2009). If not stopped by the plant antioxidants defences, this phenomenon can lead to much superior damage than the reactive species that initiate the reaction. Therefore, detailed analysis of fatty acids is important in irradiated foods. The results for the fatty acids composition, total saturated fatty acids (SFA), monounsaturated fatty acids (MUFA), polyunsaturated fatty acids (PUFA), and the ratios of PUFA/SFA and n-6/n-3 are shown in Table 3. Up to 23 fatty acids were detected, being palmitic (C16:0) and $\alpha$-linolenic (C18:3n3) acids the most abundant, in agreement to Pereira et al. (2011). Looking at the one-way ANOVA $p$-values, it is clear that the induced changes were significant. C16:0 decreased during storage while C18:3n3 increased under the same conditions, except for the results achieved with the 1 kGy dose. Other abundant fatty acids were linoleic (C18:2n6), stearic (C18:0), lignoceric (C24:0) and eicosadienoic (C20:2) acids. Both palmitoleic (C16:1) and nervonic (C24:1) acid were not detected in fresh samples or in those irradiated at $1 \mathrm{kGy}$. Fresh samples revealed higher levels of SFA $(\sim 57 \%)$ than the sum of MUFA $(\sim 1 \%)$ and PUFA ( $42 \%)$. Generally, the storage time induced positive effects increasing the levels of MUFA and PUFA and the PUFA/SFA ratio, and decreasing the levels of SFA and the n-6/n-3 ratio. Regarding the effects of gamma irradiation, the $5 \mathrm{kGy}$ dose favoured MUFA (e.g., C16:1, oleic acid (C18:1n9) and C24:1), while the $2 \mathrm{kGy}$ dose was especially effective in favouring PUFA (e.g., C18:3n3 and eicosapentaenoic acid (C20:5n3)) and the PUFA/SFA ratio. In either case, the irradiation treatment allowed obtaining watercress samples with a healthier fatty acids profile. According to some studies, a lower ratio of n-6/n-3 fatty acids is desirable in reducing the risk of many of 
the chronic diseases of high prevalence in Western societies, as well as in the developing countries (Simopoulos, 2008).

Concerning the tocopherols profile, $\alpha$-tocopherol was the most abundant isoform, followed by $\gamma$-tocopherol and $\beta$-tocopherol, in accordance with the results previously reported by Pereira et al. (2011). The most relevant result was the effect achieved with the $5 \mathrm{kGy}$ dose, particularly owing the contributions of $\alpha$-, $\gamma$-tocopherols and the total tocopherols content. The storage time also increased the total tocopherols content in non-irradiated samples, mainly due to the contribution of $\alpha$ - and $\beta$-tocopherols. It is known that tocopherols levels can increase in response to stress conditions (MunnéBosch, 2005; Yusuf et al., 2010). In these situations, the production of free radicals and reactive species, stimulated in wounded tissues and resulting from the radiolysis of water, can lead to oxidative damage. The high levels of tocopherols enhance the oxidative stability of tissues owing to its ability to protect polyunsaturated fatty acids from peroxidation and to scavenge free radicals. Additionally, $\alpha$-tocopherol plays a major role in the alleviation of stress (Munné-Bosch, 2005). Therefore, the tocopherols increase verified in this work can be related to the inaptness of some of the applied doses in conferring suitable preservation conditions to the samples during storage. Nevertheless, the observed increase confers a higher bioactivity. The observed phenomenon can also be attributed to a hormetic effect induced by the applied doses, which promote beneficial effects through mild stress (Shama \& Alderson, 2005).

\subsection{Effects on the antioxidant activity and total phenolics and flavonoids}

The antioxidant capacity of vegetables is conferred by high levels of phenolic compounds, and also of vitamin $\mathrm{C}$ (ascorbic acid), vitamin $\mathrm{E}$ (tocopherols), and carotenoids, among other compounds (Carocho \& Ferreira, 2013). The results for the 
antioxidant properties and total phenolics and flavonoids are presented in Table 4. Again, the one-way ANOVA $p$-values validated the statistically significant differences among irradiated samples. Fresh samples, analyzed immediately after harvest, revealed the lowest $\mathrm{EC}_{50}$ values (higher antioxidant activity) for the three in vitro assays of $\mathrm{DPPH}^{\circ}$ scavenging activity, reducing power and $\beta$-carotene blanching inhibition capacity. The decline in antioxidant activity during storage could probably be due to the degradation of antioxidants as a result of oxidation. It is quite clear that the $5 \mathrm{kGy}$ allowed the best results (except for TBARS formation inhibition) in maintaining the antioxidant activity, as well as in the total phenolics and flavonoids, measured in fresh samples. Note that these samples have demonstrated the highest levels of $\alpha$ - and $\gamma$ tocopherols and the total tocopherols content, which are antioxidants capable to donate phenolic hydrogen and, therefore, halt the oxidative chain reaction. Moreover, differences among the results achieved with the applied assays could be related to the dissimilar mechanisms of action involved, e.g., the $\beta$-carotene blanching inhibition assay is based on a lipophilic reaction; in the $\mathrm{DPPH}^{\circ}$ scavenging assay both electron and hydrogen atom transfer mechanisms are possible, while the reducing power assay evaluates the ability of an antioxidant to donate an electron (Carocho \& Ferreira, 2013). Overall, the total phenolic content was higher after the $7 \mathrm{~d}$ of cold storage, while flavonoids decreased under the same conditions. Similar amounts of phenolics (96-97 $\mathrm{mg} \mathrm{GAE} / \mathrm{g}$ extract) and higher levels of flavonoids (62-63 $\mathrm{mg} \mathrm{CE} / \mathrm{g}$ extract) were reported by Yazdanparast, Bahramikia and Ardestani (2008) and Bahramikia and Yazdanparast (2010) in hydro-ethanolic extracts of watercress samples from Iran. These samples also revealed a comparable TBARS inhibition capacity $(0.27 \mathrm{mg} / \mathrm{mL})$. In contrast, Pereira et al. (2011) described lower values for phenolics ( $~ 50.42 \mathrm{mg} \mathrm{GAE} / \mathrm{g}$ 
extract) but a similar content in flavonoids $(\sim 35.17 \mathrm{mg} \mathrm{CE} / \mathrm{g}$ extract $)$ in methanolic extracts, comparing to our fresh samples and those irradiated at $5 \mathrm{kGy}$.

The production of phenolic compounds during storage can be stimulated by the wounding-induced stress caused on the watercress tissues, which is a plant defence mechanism to withstand the stress conditions (Heredia \& Cisneros-Zevallos, 2009; Pérez-Gregorio, García-Falcón, Simal-Gándara, 2011). Besides, and as mentioned above, the free radicals and reactive species generated during the irradiation process may act as stress signals and may trigger stress responses in vegetables, resulting in increased antioxidant synthesis (e.g., tocopherols), which enforces the hormesis effect idea. Vaishnav et al. (2015) observed that irradiated samples of minimally processed cauliflower preserved the total phenolic content over the course of storage, while the non-irradiated samples suffered a reduction of these compounds. The same authors also observed a no significant change in the flavonoid content due to radiation processing; however, as verified in our study, a time dependent reduction was observed during storage. In other work conducted by Tripathi et al. (2013) it was found an increase in the total phenolic content of irradiated minimally processed ash gourd cubes, compared to the non-irradiated control samples, at all stages of storage. The increase in total phenolics of irradiated plants has also been attributed to depolymerisation and dissolution of the cell wall polysaccharides, which facilitates higher extractability (Bhat, Sridhar, Tomita, \& Tomita-Yokotanib, 2007).

\subsection{Overall effect on quality}

The effects of gamma irradiation on the overall quality of fresh-cut watercress during cold storage were accessed through a LDA. The basic purpose of this discriminant analysis was finding the irradiation dose (categorical dependent variable) that 
maintained quality profiles (set of quantitative independent variables) of the fresh samples throughout the cold storage time. The significant independent variables were selected following the stepwise method of the LDA, according to the Wilks' $\lambda$ test. Only variables with a statistically significant classification performance $(p<0.05)$ were kept in the analysis.

The discriminant model selected 4 significant functions, which included $100.0 \%$ of the observed variance. Figure 1 represents the three first functions (function 1: $47.6 \%$, function $2: 25.7 \%$, function $3: 15.6 \%$ ), which allowed the complete individualization of each gamma irradiation dose from the non-stored control. From the 58 studied variables, the discriminant model considered fructose, capric acid (C10:0), pentadecanoic acid (C15:0), C16:1, C18:3n3, C20:5n3, $\gamma$-tocopherol and $\beta$-carotene bleaching inhibition as those with significant discriminant ability. From the collective contribution of the three discriminant functions it is obvious that markers corresponding to the $2 \mathrm{kGy}$ dose were those placed nearest to the fresh control ones, indicating that this treatment would be the preferable choice to preserve the postharvest quality of these samples. In agreement with our results, a report of the Joint FAO/IAEA Division of Nuclear Techniques in Food and Agriculture (IAEA, 2006), recommends irradiation doses up to $2 \mathrm{kGy}$ for processing watercress as well as for other green vegetables such as endive, chicory, lettuce, arugula, spinach and cabbage. Nevertheless, the result obtained in this study for the $5 \mathrm{kGy}$ dose, which gave a high antioxidant activity and detachable levels of $\mathrm{C} 18: 1 \mathrm{n} 3, \mathrm{C} 18: 3 \mathrm{n} 3$ and total tocopherols, should also be considered when aiming to obtain a final product with an enhanced health-promoting composition.

\section{Conclusions}


The colour parameters were not affected by the applied irradiation doses. The storage time decreased the amounts of proteins, carbohydrates, fructose and glucose. Contrariwise, the contents of malic and fumaric acids, MUFA, PUFA and total phenolics were higher past $7 \mathrm{~d}$ of cold storage. The $2 \mathrm{kGy}$ dose preserved high levels of reducing sugars and favoured PUFA; while samples irradiated at $5 \mathrm{kGy}$ revealed high contents of sucrose and MUFA. In either case, watercress samples with a healthier fatty acids profile were obtained. Concerning tocopherols, the most relevant result was achieved with the $5 \mathrm{kGy}$ dose, particularly owing the contributions of $\alpha$ - (the major isoform) and $\gamma$-tocopherols. This dose better preserved the antioxidant activity and total flavonoids. Overall, samples irradiated at $2 \mathrm{kGy}$ were those with the most similar quality profiles to the non-stored control samples. In further studies, the effects of gamma irradiation on physiological and other quality parameters of fresh-cut watercress during cold storage, as well as the combination with other preservation technologies will be interesting.

\section{Acknowledgements}

The authors are grateful to PRODER research project $n^{\circ}$ 53514, AROMAP, for financial support of the work; to the Foundation for Science and Technology (FCT, Portugal) for financial support to CIMO (PEst-OE/AGR/UI0690/2014), C2TN (RECI/AAGTEC/0400/2012), J. Pinela (SFRH/BD/92994/2013), J.C.M. Barreira (SFRH/BPD/72802/2010) and L. Barros (SFRH/BPD/107855/2015); and to FCT/MEC for financial support to REQUIMTE/LAQV (UID/QUI/50006/2013 POCI/01/0145/FERDER/007265) through national funds and co-financed by FEDER, under the Partnership Agreement PT2020. 


\section{Conflict of interest}

The authors declare that there are no conflicts of interest.

\section{References}

AOAC (2005). Official methods of analysis of AOAC international. (18 ${ }^{\text {th }}$ ed.). Gaithersburg, MD, USA: AOAC International.

Apelblat, A. (2014). Citric acid. Switzerland: Springer International Publishing.

Bahramikia, S., \& Yazdanparast, R. (2010). Antioxidant efficacy of Nasturtium officinale extracts using various in vitro assay systems. Journal of Acupuncture and Meridian Studies, 3, 283-290.

Barrett, D. M., Beaulieu, J. C., \& Shewfelt, R. (2010). Color, flavor, texture, and nutritional quality of fresh-cut fruits and vegetables: desirable levels, instrumental and sensory measurement, and the effects of processing. Critical Reviews in Food Science and Nutrition, 50, 369-389.

Barros, L., Carvalho, A. M., Sá Morais, J., \& Ferreira, I. C. F. R. (2010). Strawberry-tree, blackthorn and rose fruits: Detailed characterisation in nutrients and phytochemicals with antioxidant properties. Food Chemistry, 120, 1, 247-254

Bhat, R., Sridhar, K. R., Tomita, Y., \& Tomita-Yokotanib, K. (2007). Effect of ionizing radiation on antinutritional features of velvet bean seeds (Mucuna pruriens). Food Chemistry, 103, 860-866.

Carocho, M., \& Ferreira, I. C. F. R. (2013) A review on antioxidants, prooxidants and related controversy: natural and synthetic compounds, screening and analysis methodologies and future perspectives. Food and Chemical Toxicology, 51, 15-25.

Dey, P. M., \& Harborne, J. B. (1997). Plant biochemistry. London, UK: Academic Press.

Fan, X., \& Sokorai, K. J. B. (2011). Changes in quality, liking, and purchase intent of irradiated fresh-cut spinach during storage. Journal of Food Science, 76, 363-368. 
Fanaro, G. B., Hassimotto, N. M. A., Bastos, D. H. M., \& Villavicencio, A. L. C. H. (2015). Effects of $\gamma$-radiation on microbial load and antioxidant proprieties in green tea irradiated with different water activities. Radiation Physics and Chemistry, 207, 4046.

Fernandes, Â., Antonio, A. L., Barreira, J. C. M., Oliveira, M. B. P. P., Martins, A., \& Ferreira, I. C. F. R. (2012). Effects of gamma irradiation on physical parameters of Lactarius deliciosus wild edible mushrooms. Postharvest Biology and Technology, $74,79-84$

Ferreira, I. C. F. R., Barros, L., \& Abreu, R. M. V. (2009). Antioxidants in wild mushrooms. Current Medicinal Chemistry, 16, 1543-1560.

Francis, G. A., Gallone, A., Nychas, G. J., Sofos, J. N., Colelli, G., Amodio, M. L., \& Spano, G. (2012). Factors affecting quality and safety of fresh-cut produce. Critical Reviews in Food Science and Nutrition, 52, 595-610.

Hallman, G.J. (2016). Process control in phytosanitary irradiation of fresh fruits and vegetables as a model for other phytosanitary treatment processes. Food Control, In Press. doi:10.1016/j.foodcont.2016.02.010

Heredia, J. B., \& Cisneros-Zevallos, L. (2009). The effects of exogenous ethylene and methyl jasmonate on the accumulation of phenolic antioxidants in selected whole and wounded fresh produce. Food Chemistry, 115, 1500-1508.

Hinojosa, A., Silveira, A. C., Ospina, M., Char, C., Sáenz, C., \& Escalona, V. H. (2012). Safety of ready-to-eat watercress using environmentally friendly sanitization methods. Journal of Food Quality, 36, 66-76.

IAEA (2006). Use of irradiation to ensure the hygienic quality of fresh, pre-cut fruits and vegetables and other minimally processed food of plant origin. Proceedings of a final research coordination meeting organized by the Joint FAO/IAEA Programme 
of Nuclear Techniques in Food and Agriculture and held in Islamabad, Pakistan, 22-30 July 2005. Vienna, Austria: International Atomic Energy Agency.

ICGFI (1999). Facts about Food Irradiation: a series of Fact Sheets from the International Consultative Group on Food Irradiation, International Consultative Group on Food Irradiation. Vienna, Austria: International Atomic Energy Agency.

Molins, R. A. (2001). Food irradiation: principles and applications. USA: John Wiley \& Sons0-471-35634-4

Munné-Bosch, S. (2005). The role of $\alpha$-tocopherol in plant stress tolerance. Journal of Plant Physiology, 162, 743-748.

Nikolopoulou, D., Grigorakis, K., Stasini, M., Alexis, M. N., \& Iliadis, K. (2007). Differences in chemical composition of field pea (Pisum sativum) cultivars: effects of cultivation area and year. Food Chemistry, 103, 847-852.

Nunes, T. P., Martins, C. G., Faria, A. F., Bíscola, V., Souza, K. L. O., Mercadante, A. Z., Cordenunsi, B. R., \& Landgraf, M. (2013). Changes in total ascorbic acid and carotenoids in minimally processed irradiated Arugula (Eruca sativa Mill) stored under refrigeration. Radiation Physics and Chemistry, 90, 125-130.

Pereira, C., Barreira, J. C. M., Calhelha, R. C., Lopes, M., Queiroz, M. J. R. P., Vilas-Boas, M., Barros, L., \& Ferreira, I. C. F. R. (2015b). Is honey able to potentiate the antioxidant and cytotoxic properties of medicinal plants consumed as infusions for hepatoprotective effects? Food \& Function, 6, 1435-1442.

Pereira, C., Barros, L., Carvalho, A. M., \& Ferreira, I. C. F. R. (2011). Nutritional composition and bioactive properties of commonly consumed wild greens: potential sources for new trends in modern diets. Food Research International, 44, 26342640. 
Pereira, C., Barros, L., Carvalho, A. M., \& Ferreira, I. C. F. R. (2013). Use of UFLC-PDA for the analysis of organic acids in thirty-five species of food and medicinal plants. Food Analytical Methods, 6, 1337-1344.

Pereira, E., Antonio, A. L., Barreira, J. C. M., Barros, L., Bento, A., \& Ferreira, Isabel, C. F. R. (2015a). Gamma irradiation as a practical alternative to preserve the chemical and bioactive wholesomeness of widely used aromatic plants. Food Research International, 67, 338-348.

Pérez-Gregorio, M. R., García-Falcón, M. S., \& Simal-Gándara, J. (2011) Flavonoids changes in fresh-cut onions during storage in different packaging systems. Food Chemistry, 124, 652-658.

Pinela, J., \& Ferreira, I. C. F. R. (2015). Non-thermal physical technologies to decontaminate and extend the shelf-life of fruits and vegetables: trends aiming at quality and safety. Critical Reviews in Food Science and Nutrition, in press.

Ramos, B., Miller, F. A., Brandão, T. R. S., Teixeira, P., \& Silva, C. L. M. (2013). Fresh fruits and vegetables - An overview on applied methodologies to improve its quality and safety. Innovative Food Science and Emerging Technologies, 20, 1-15.

Rose, P., Won, Y. K., Ong, C. N., \& Whiteman, M. (2005). Beta-phenylethyl and 8methylsulphinyloctyl isothiocyanates, constituents of watercress, suppress LPS induced production of nitric oxide and prostaglandin E2 in RAW 264.7 macrophages. Nitric Oxide, 12, 237-243.

Sadeghi, H., Mostafazadeh, M., Sadeghi, H., Naderian, M., Barmak, M. J., Talebianpoor, M. S., \& Mehraban, F. (2014). In vivo anti-inflammatory properties of aerial parts of Nasturtium officinale. Pharmaceutical Biology, 52, 169-174.

Semelová, M., Čuba, V., John, J., \& Múčka, V. (2008). Radiolysis of oxalic and citric acids using gamma rays and accelerated electrons. Radiation Physics and Chemistry, 77, $884-888$. 
Shama, G., \& Alderson, P. (2005). UV hormesis in fruits: a concept ripe for commercialisation. Trends in Food Science \& Technology, 16, 128-136.

Sillani, S., \& Nassivera, F. (2015). Consumer behavior in choice of minimally processed vegetables and implications for marketing strategies. Trends in Food Science \& Technology, in press.

Silveira, A. C., Araneda, C., Hinojosa, A., \& Escalona, V. H. (2014). Effect of nonconventional modified atmosphere packaging on fresh cut watercress (Nasturtium officinale R. Br.) quality. Postharvest Biology and Technology, 92, 114-120.

Simopoulos, A. P. (2008). The importance of the omega-6/omega-3 fatty acid ratio in cardiovascular disease and other chronic diseases. Experimental Biology and Medicine, 233, 674-688.

Trigo, M. J., Sousa, M. B., Sapata, M. M., Ferreira, A., Curado, T., Andrada, L., Botelho, M. L., \& Veloso, M. G. (2009). Radiation processing of minimally processed vegetables and aromatic plants. Radiation Physics and Chemistry, 78, 659-663.

Tripathi, J., Chatterjee, S., Vaishnav, J., Variyar, P. S., \& Sharma, A. (2013). Gamma irradiation increases storability and shelf life of minimally processed ready-to-cook (RTC) ash gourd (Benincasa hispida) cubes. Postharvest Biology and Technology, $76,17-25$.

Uritani, I., \& Asahi, T. (1980). Respiration and related metabolic activity in wounded and infected tissues. In P. K. Stumpf, \& E. E. Conn (Eds.), The biochemistry of plants: a comprehensive treatise, Vol. 2. Metabolism and respiration (pp. 463-485). London: Academic Press.

Vaishnav, J., Adiani, V., \& Variyar, P. S. (2015). Radiation processing for enhancing shelf life and quality characteristics of minimally processed ready-to-cook (RTC) cauliflower (Brassica oleracea). Food Packaging and Shelf Life, 5, 50-55. 
WHO (1999). High-dose irradiation: wholesomeness of food irradiated with doses above 10 kGy. Report of a Joint FAO/IAEA/WHO Study Group. Geneva, Switzerland: World Health Organization.

Workneh, T. S., Osthoff, G., \& Steyn, M. (2012). Effects of preharvest treatment, disinfections, packaging and storage environment on quality of tomato. Journal of Food Science and Technology, 49, 685-694.

Yazdanparast, R., Bahramikia, S., \& Ardestani, A. (2008). Nasturtium officinale reduces oxidative stress and enhances antioxidant capacity in hypercholesterolaemic rats. Chemico-Biological Interactions, 172, 176-184.

Yusuf, M. A., Kumar, D., Rajwanshi, R., Strasser, R. J., Tsimilli-Michael, M., Govindjee, \& Sarin, N. B. (2010). Overexpression of $\gamma$-tocopherol methyl transferase gene in transgenic Brassica juncea plants alleviates abiotic stress: Physiological and chlorophyll a fluorescence measurements. Biochimica et Biophysica Acta, 1797, $1428-1438$.

Zeng, F., Luo, Z., Xie, J., \& Feng, S. (2015). Gamma radiation control quality and lignification of bamboo shoots (Phyllostachys praecox f. prevernalis.) stored at low temperature. Postharvest Biology and Technology, 102, 17-24. 


\section{Figure captions}

Figure 1. Biplot of object scores (gamma irradiation doses) and component loadings (evaluated quality parameters). 
Table 1. Combined effects of gamma irradiation and cold storage on colour parameters, TSS (\%) and pH values of fresh-cut watercress samples. ${ }^{1}$

\begin{tabular}{|c|c|c|c|c|c|c|c|c|}
\hline & \multirow{2}{*}{$\frac{\text { Fresh samples }}{\text { Non-stored control }}$} & \multicolumn{4}{|c|}{ Irradiated samples stored at $4 \pm 1^{\circ} \mathrm{C}$ for $7 \mathrm{~d}$} & \multicolumn{3}{|c|}{$p$-values } \\
\hline & & 0 kGy & $1 \mathrm{kGy}$ & $2 \mathrm{kGy}$ & 5 kGy & Homoscedasticity $^{2}$ & Normal distribution $^{3}$ & 1-way ANOVA ${ }^{4}$ \\
\hline$L^{*}$ & $39 \pm 3^{\mathrm{b}}$ & $45 \pm 2^{\mathrm{a}}$ & $42 \pm 4^{\mathrm{ab}}$ & $44 \pm 5^{\mathrm{a}}$ & $45 \pm 3^{\mathrm{a}}$ & 0.267 & 0.272 & 0.003 \\
\hline$a^{*}$ & $-17 \pm 2$ & $-18 \pm 1$ & $-17 \pm 2$ & $-18 \pm 2$ & $-17 \pm 1$ & 0.324 & 0.058 & 0.408 \\
\hline$b^{*}$ & $27 \pm 2^{\mathrm{b}}$ & $31 \pm 4^{\mathrm{a}}$ & $29 \pm 3^{\mathrm{ab}}$ & $31 \pm 3^{\mathrm{ab}}$ & $29 \pm 2^{\mathrm{ab}}$ & 0.104 & 0.156 & 0.038 \\
\hline TSS & $3.4 \pm 0.1^{\mathrm{b}}$ & $3.2 \pm 0.1^{\mathrm{c}}$ & $3.7 \pm 0.1^{\mathrm{a}}$ & $3.5 \pm 0.1^{\mathrm{b}}$ & $3.2 \pm 0.1^{\mathrm{c}}$ & 0.092 & 0.038 & $<0.001$ \\
\hline $\mathrm{pH}$ & $5.49 \pm 0.04^{\mathrm{a}}$ & $5.40 \pm 0.05^{\mathrm{b}}$ & $5.34 \pm 0.03^{\mathrm{b}}$ & $5.36 \pm 0.03^{b}$ & $5.56 \pm 0.03^{\mathrm{a}}$ & $<0.001$ & 0.031 & $<0.001$ \\
\hline
\end{tabular}

${ }^{1}$ The results are presented as the mean \pm standard deviation.

${ }^{2}$ Homoscedasticity among different doses was tested by the Levene test: homoscedasticity, $p>0.05$; heteroscedasticity, $p<0.05$.

${ }_{4}^{3}$ Normal distribution of the residuals was evaluated using Shapiro-Wilk test.

${ }^{4} p<0.05$ indicates that the mean value of the evaluated parameter of at least one irradiation dose differs from the others (in this case multiple comparison tests were performed).

For each treatment, means within a row with different letters differ significantly $(p<0.05)$

$L^{*}$ : darkness ${ }^{(0)} \leftrightarrow$ lightness ${ }^{(100)} ; a^{*}$ : redness ${ }^{(+)} \leftrightarrow$ greenness $^{(-)} ; b^{*}$ : yellowness ${ }^{(+)} \leftrightarrow$ blueness ${ }^{(-)}$. 
Table 2. Combined effects of gamma irradiation and cold storage on the proximate composition ( $\mathrm{g} / 100 \mathrm{~g} \mathrm{fw}$ ), energetic value (kcal/100 $\mathrm{g}$ fw), individual sugars (mg/100 $\mathrm{g}$ $\mathrm{fw})$ and organic acids $(\mathrm{mg} / 100 \mathrm{~g} \mathrm{fw})$ of fresh-cut watercress samples. ${ }^{1}$

\begin{tabular}{|c|c|c|c|c|c|c|c|c|}
\hline & \multirow{2}{*}{$\frac{\text { Fresh samples }}{\text { Non-stored control }}$} & \multicolumn{4}{|c|}{ Irradiated samples stored at $4 \pm 1{ }^{\circ} \mathrm{C}$ for $7 \mathrm{~d}$} & \multicolumn{3}{|c|}{$p$-values } \\
\hline & & $0 \mathrm{kGy}$ & $1 \mathrm{kGy}$ & $2 \mathrm{kGy}$ & $5 \mathrm{kGy}$ & Homoscedasticity $^{2}$ & Normal distribution $^{3}$ & 1-way ANOVA ${ }^{4}$ \\
\hline Moisture & $93 \pm 1^{b}$ & $94 \pm 1^{\mathrm{a}}$ & $94 \pm 1^{\mathrm{ab}}$ & $94 \pm 1^{\mathrm{ab}}$ & $94 \pm 1^{\mathrm{ab}}$ & 0.300 & 0.051 & 0.010 \\
\hline Ash & $0.94 \pm 0.05^{\mathrm{a}}$ & $0.88 \pm 0.05^{\mathrm{ab}}$ & $0.87 \pm 0.03^{\mathrm{ab}}$ & $0.84 \pm 0.02^{\mathrm{b}}$ & $0.90 \pm 0.05^{\mathrm{ab}}$ & $<0.001$ & 0.006 & 0.016 \\
\hline Proteins & $2.2 \pm 0.1^{\mathrm{a}}$ & $1.9 \pm 0.1^{\mathrm{bc}}$ & $1.9 \pm 0.1^{\mathrm{c}}$ & $2.0 \pm 0.1^{\mathrm{b}}$ & $2.0 \pm 0.1^{\mathrm{bc}}$ & 0.859 & 0.026 & $<0.001$ \\
\hline Fat & $0.14 \pm 0.05$ & $0.13 \pm 0.02$ & $0.12 \pm 0.01$ & $0.14 \pm 0.05$ & $0.13 \pm 0.01$ & $<0.001$ & $<0.001$ & 0.261 \\
\hline Carbohydrates & $3.6 \pm 0.1^{\mathrm{a}}$ & $3.0 \pm 0.1^{\mathrm{b}}$ & $3.0 \pm 0.2^{\mathrm{b}}$ & $3.0 \pm 0.1^{\mathrm{b}}$ & $2.9 \pm 0.1^{\mathrm{b}}$ & 0.068 & 0.001 & $<0.001$ \\
\hline Energy & $24.5 \pm 0.3^{\mathrm{a}}$ & $20.8 \pm 0.5^{\mathrm{bc}}$ & $20.7 \pm 0.5^{\mathrm{c}}$ & $21.5 \pm 0.5^{\mathrm{b}}$ & $20.8 \pm 0.3^{\mathrm{bc}}$ & 0.180 & $<0.001$ & $<0.001$ \\
\hline Fructose & $110 \pm 3^{\mathrm{a}}$ & $69 \pm 3^{b}$ & $43 \pm 4^{c}$ & $71 \pm 5^{\mathrm{b}}$ & $42 \pm 2^{c}$ & 0.316 & $<0.001$ & $<0.001$ \\
\hline Glucose & $70 \pm 2^{a}$ & $31 \pm 4^{\mathrm{c}}$ & $17 \pm 5^{\mathrm{d}}$ & $39 \pm 9^{b}$ & $39 \pm 4^{b}$ & 0.005 & 0.003 & $<0.001$ \\
\hline Sucrose & $23 \pm 5^{c}$ & $46 \pm 4^{\mathrm{ab}}$ & $42 \pm 3^{b}$ & $42 \pm 5^{b}$ & $50 \pm 5^{\mathrm{a}}$ & 0.368 & 0.003 & $<0.001$ \\
\hline Total sugars & $203 \pm 3^{\mathrm{a}}$ & $145 \pm 4^{\mathrm{b}}$ & $102 \pm 6^{\mathrm{d}}$ & $153 \pm 11^{\mathrm{b}}$ & $132 \pm 5^{\mathrm{c}}$ & 0.005 & 0.002 & $<0.001$ \\
\hline Oxalic acid & $754 \pm 24^{b}$ & $630 \pm 9^{d}$ & $850 \pm 25^{\mathrm{a}}$ & $714 \pm 38^{c}$ & $656 \pm 36^{\mathrm{d}}$ & 0.007 & 0.010 & $<0.001$ \\
\hline Malic acid & $73 \pm 2^{\mathrm{d}}$ & $286 \pm 8^{c}$ & $365 \pm 25^{b}$ & $445 \pm 23^{\mathrm{a}}$ & $325 \pm 68^{b c}$ & $<0.001$ & $<0.001$ & $<0.001$ \\
\hline Citric acid & $109 \pm 4^{\mathrm{a}}$ & $98 \pm 8^{b}$ & $66 \pm 4^{c}$ & $44 \pm 4^{\mathrm{d}}$ & $38 \pm 4^{\mathrm{e}}$ & 0.088 & $<0.001$ & $<0.001$ \\
\hline Fumaric acid & $0.35 \pm 0.02^{\mathrm{d}}$ & $1.50 \pm 0.05^{\mathrm{b}}$ & $1.25 \pm 0.05^{\mathrm{c}}$ & $1.24 \pm 0.05^{\mathrm{c}}$ & $1.63 \pm 0.05^{\mathrm{a}}$ & 0.088 & $<0.001$ & $<0.001$ \\
\hline Total organic acids & $936 \pm 22^{d}$ & $1015 \pm 22^{c}$ & $1282 \pm 12^{\mathrm{a}}$ & $1205 \pm 33^{b}$ & $1021 \pm 92^{c}$ & $<0.001$ & 0.001 & $<0.001$ \\
\hline
\end{tabular}

${ }^{1}$ The results are presented as the mean \pm standard deviation.

${ }^{2}$ Homoscedasticity among different doses was tested by the Levene test: homoscedasticity, $p>0.05$; heteroscedasticity, $p<0.05$.

${ }^{3}$ Normal distribution of the residuals was evaluated using Shapiro-Wilk test.

${ }_{p}^{4}<0.05$ indicates that the mean value of the evaluated parameter of at least one irradiation dose differs from the others (in this case multiple comparison tests were performed).

For each treatment, means within a row with different letters differ significantly $(p<0.05)$. 
Table 3. Combined effects of gamma irradiation and cold storage on fatty acids (relative percentage) and tocopherols (mg/100 $\mathrm{g}$ fw) composition of fresh-cut watercress samples. ${ }^{1}$

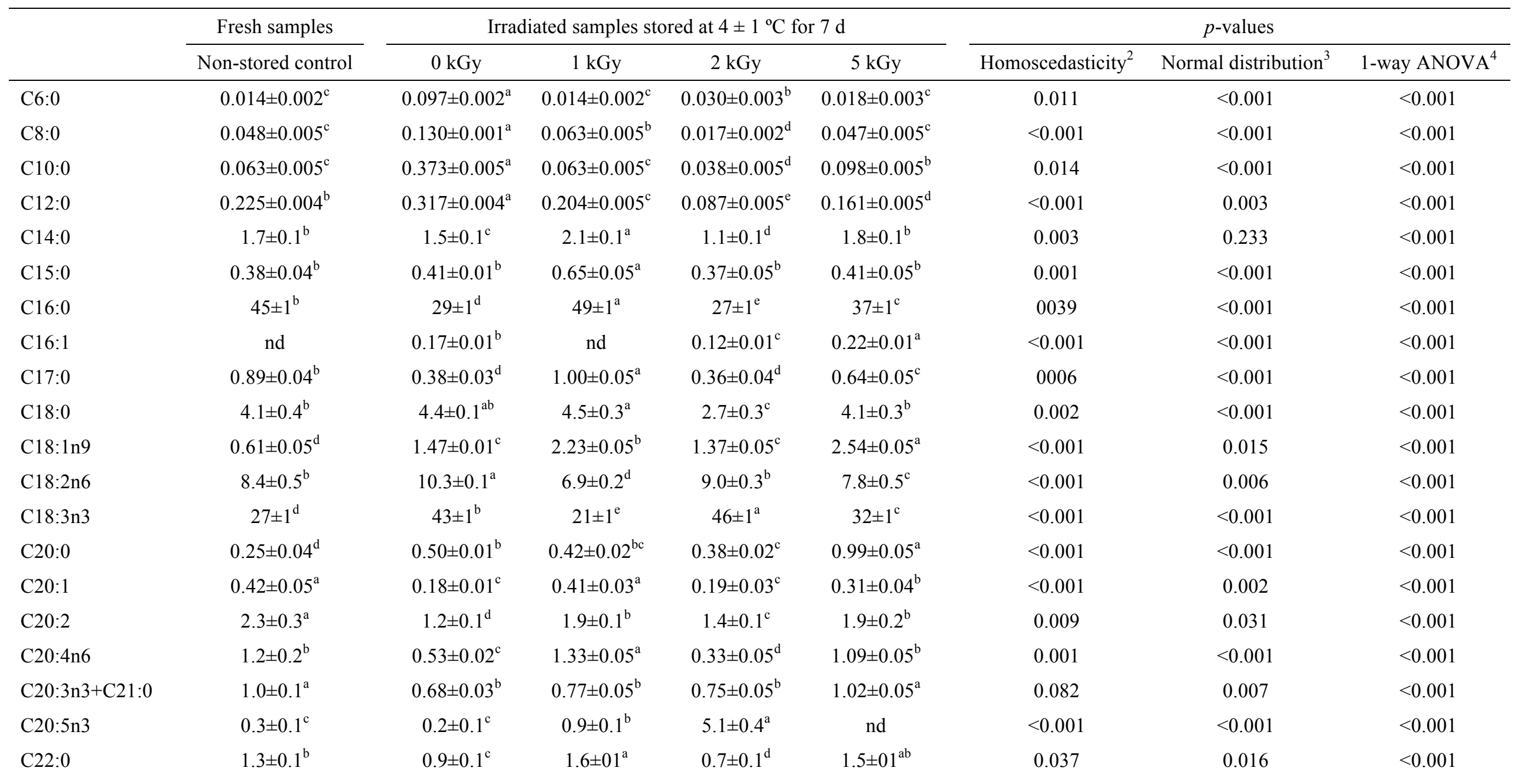




\begin{tabular}{|c|c|c|c|c|c|c|c|c|}
\hline $\mathrm{C} 22: 2$ & $1.6 \pm 0.1^{\mathrm{a}}$ & $0.57 \pm 0.01^{\mathrm{d}}$ & $1.3 \pm 0.1^{\mathrm{b}}$ & $0.44 \pm 0.05^{\mathrm{e}}$ & $1.1 \pm 0.1^{\mathrm{c}}$ & $<0.001$ & 0.002 & $<0.001$ \\
\hline $\mathrm{C} 24: 0$ & $2.8 \pm 0.2^{\mathrm{bc}}$ & $2.6 \pm 0.1^{\mathrm{c}}$ & $3.6 \pm 0.3^{\mathrm{a}}$ & $2.0 \pm 0.1^{\mathrm{d}}$ & $3.2 \pm 0.5^{\mathrm{b}}$ & 0.003 & 0.134 & $<0.001$ \\
\hline $\mathrm{C} 24: 1$ & nd & $0.8 \pm 0.1^{\mathrm{b}}$ & nd & $0.54 \pm 0.05^{\mathrm{c}}$ & $1.7 \pm 0.1^{\mathrm{a}}$ & $<0.001$ & $<0.001$ & $<0.001$ \\
\hline Total SFA & $57 \pm 1^{b}$ & $40 \pm 1^{\mathrm{d}}$ & $63 \pm 1^{a}$ & $35 \pm 1^{\mathrm{e}}$ & $50 \pm 1^{\mathrm{c}}$ & 0.010 & 0.001 & $<0.001$ \\
\hline Total MUFA & $1.0 \pm 0.1^{\mathrm{d}}$ & $2.6 \pm 0.2^{\mathrm{b}}$ & $2.6 \pm 0.1^{\mathrm{b}}$ & $2.2 \pm 0.2^{\mathrm{c}}$ & $4.8 \pm 0.4^{\mathrm{a}}$ & $<0.001$ & $<0.001$ & $<0.001$ \\
\hline Total PUFA & $42 \pm 1^{\mathrm{d}}$ & $57 \pm 1^{\mathrm{b}}$ & $34 \pm 1^{\mathrm{e}}$ & $63 \pm 1^{\mathrm{a}}$ & $45 \pm 1^{c}$ & 0.001 & $<0.001$ & $<0.001$ \\
\hline PUFA/SFA & $0.74 \pm 0.02^{\mathrm{d}}$ & $1.41 \pm 0.05^{\mathrm{b}}$ & $0.55 \pm 0.01^{\mathrm{e}}$ & $1.80 \pm 0.05^{\mathrm{a}}$ & $0.90 \pm 0.04^{\mathrm{c}}$ & $<0.001$ & $<0.001$ & $<0.001$ \\
\hline$n-6 / n-3$ & $0.47 \pm 0.03^{\mathrm{a}}$ & $0.28 \pm 0.01^{\mathrm{c}}$ & $0.50 \pm 0.02^{\mathrm{a}}$ & $0.22 \pm 0.01^{\mathrm{d}}$ & $0.36 \pm 0.01^{\mathrm{b}}$ & $<0.001$ & 0.001 & $<0.001$ \\
\hline$\alpha$-tocopherol & $0.50 \pm 0.03^{\mathrm{c}}$ & $1.25 \pm 0.05^{\mathrm{a}}$ & $0.96 \pm 0.05^{\mathrm{b}}$ & $0.26 \pm 0.01^{\mathrm{d}}$ & $1.21 \pm 0.05^{\mathrm{a}}$ & 0.001 & $<0.001$ & $<0.001$ \\
\hline$\beta$-tocopherol & $0.011 \pm 0.001^{\mathrm{b}}$ & $0.021 \pm 0.004^{\mathrm{a}}$ & $0.011 \pm 0.002^{\mathrm{b}}$ & $0.005 \pm 0.001^{\mathrm{c}}$ & $0.012 \pm 0.001^{\mathrm{b}}$ & $<0.001$ & 0.001 & $<0.001$ \\
\hline$\gamma$-tocopherol & $0.038 \pm 0.003^{\mathrm{c}}$ & $0.067 \pm 0.005^{\mathrm{b}}$ & $0.070 \pm 0.003^{\mathrm{b}}$ & $0.041 \pm 0.001^{\mathrm{c}}$ & $0.22 \pm 0.01^{\mathrm{a}}$ & 0.001 & $<0.001$ & $<0.001$ \\
\hline Total tocopherols & $0.55 \pm 0.04^{\mathrm{d}}$ & $1.34 \pm 0.05^{\mathrm{b}}$ & $1.04 \pm 0.05^{\mathrm{c}}$ & $0.31 \pm 0.01^{\mathrm{e}}$ & $1.44 \pm 0.05^{\mathrm{a}}$ & 0.003 & $<0.001$ & $<0.001$ \\
\hline
\end{tabular}

\footnotetext{
The results are presented as the mean \pm standard deviation.
${ }^{2}$ Homoscedasticity among different doses was tested by the Levene test: homoscedasticity, $p>0.05$; heteroscedasticity, $p<0.05$.
}

${ }^{3}$ Normal distribution of the residuals was evaluated using Shapiro-Wilk test.

${ }_{p}^{4}<0.05$ indicates that the mean value of the evaluated parameter of at least one irradiation dose differs from the others (in this case multiple comparison tests were performed).

For each treatment, means within a row with different letters differ significantly $(p<0.05)$.

Caproic acid (C6:0); Caprylic acid (C8:0); Capric acid (C10:0); Lauric acid (C12:0); Myristic acid (C14:0); Pentadecanoic acid (C15:0); Palmitic acid (C16:0); Palmitoleic acid (C16:1);

Heptadecanoic acid (C17:0); Stearic acid (C18:0); Oleic acid (C18:1n9); Linoleic acid (C18:2n6); $\alpha$-Linolenic acid (C18:3n3); Arachidic acid (C20:0); cis-11-Eicosenoic acid (C20:1); cis-11,14-

Eicosadienoic acid (C20:2); Arachidonic acid (C20:4n6); cis-11,14,17-Eicosatrienoic acid and Heneicosanoic acid (C20:3n3 + C21:0); cis-5,8,11,14,17-Eicosapentaenoic acid (C20:5n3);

Behenic acid (C22:0); cis-13,16-Docosadienoic acid (C22:2); Lignoceric acid (C24:0); Nervonic acid (C24:1).

SFA: saturated fatty acids; MUFA: monounsaturated fatty acids; PUFA: polyunsaturated fatty acids; nd: not detected. 
Table 4. Combined effects of gamma irradiation and cold storage on the antioxidant activity $\left(\mathrm{EC}_{50}\right.$ values, $\mathrm{mg} / \mathrm{mL}$ ) and total phenolics (mg GAE/g extract) and flavonoids (mg CE/g extract) of fresh-cut watercress samples.

\begin{tabular}{|c|c|c|c|c|c|c|c|c|}
\hline & \multirow{2}{*}{$\frac{\text { Fresh samples }}{\text { Non-stored control }}$} & \multicolumn{4}{|c|}{ Irradiated samples stored at $4 \pm 1{ }^{\circ} \mathrm{C}$ for $7 \mathrm{~d}$} & \multicolumn{3}{|c|}{$p$-values } \\
\hline & & 0 kGy & $1 \mathrm{kGy}$ & 2 kGy & $5 \mathrm{kGy}$ & Homoscedasticity $^{2}$ & Normal distribution $^{3}$ & 1-way ANOVA ${ }^{4}$ \\
\hline $\mathrm{DPPH}^{\circ}$ scavenging activity & $0.49 \pm 0.01^{\mathrm{e}}$ & $0.81 \pm 0.01^{\mathrm{c}}$ & $0.85 \pm 0.01^{\mathrm{b}}$ & $1.01 \pm 0.02^{\mathrm{a}}$ & $0.58 \pm 0.01^{\mathrm{d}}$ & 0.007 & $<0.001$ & $<0.001$ \\
\hline$\beta$-carotene blanching inhibition & $0.33 \pm 0.02^{\mathrm{e}}$ & $0.62 \pm 0.01^{\mathrm{c}}$ & $1.27 \pm 0.02^{\mathrm{a}}$ & $0.95 \pm 0.02^{b}$ & $0.53 \pm 0.01^{\mathrm{d}}$ & 0.036 & $<0.001$ & $<0.001$ \\
\hline TBARS formation inhibition & $0.27 \pm 0.01^{\mathrm{b}}$ & $0.21 \pm 0.01^{\mathrm{c}}$ & $0.28 \pm 0.01^{\mathrm{b}}$ & $0.27 \pm 0.01^{\mathrm{b}}$ & $0.50 \pm 0.01^{\mathrm{a}}$ & 0.183 & $<0.001$ & $<0.001$ \\
\hline Total flavonoids & $36 \pm 1^{\mathrm{a}}$ & $25 \pm 1^{\mathrm{c}}$ & $26 \pm 2^{c}$ & $21 \pm 2^{\mathrm{d}}$ & $34 \pm 2^{b}$ & $<0.001$ & $<0.001$ & $<0.001$ \\
\hline
\end{tabular}

${ }^{1}$ The results are presented as the mean \pm standard deviation.
${ }^{2}$ Homoscedasticity among different doses was tested by the Levene test: homoscedasticity, $p>0.05$; heteroscedasticity, $p<0.05$.

${ }^{3}$ Normal distribution of the residuals was evaluated using Shapiro-Wilk test.

${ }_{p}^{4}<0.05$ indicates that the mean value of the evaluated parameter of at least one irradiation dose differs from the others (in this case multiple comparison tests were performed).

For each treatment, means within a row with different letters differ significantly $(p<0.05)$.

GAE: gallic acid equivalents; CE: catechin equivalents. 